\title{
Contemporary Medical Qigong: Introduction to Holo-Cosmic Qigong
}

\author{
Abraham Shue Yan Poon \\ The Water Harmony Society, Hong Kong, China
}

\begin{abstract}
The word of "qi" means the air. That is the breathing air exercise of changing air for the body. The oxygen is breathed in and the carbon dioxide is going out. It is including lute style breathing, lower part breathing, skin breathing, acupuncture points breathing, baby breathing, etc. Also, there is breathing in long and out, short, one in and three out, counting number, etc. There are so many different kinds method and the effect or result will be totally different. So, we call it helping-life at ancient. It had a completed human medical theory for fundamental to make the life freedom and living colorful.
\end{abstract}

Keywords: qi, Holo-Cosmic Qigong, 20 characters

\section{Introduction}

The charter of Qigong was folding down with our thousands history. The strong standing point was set up because 1980's approved by modernized science. We cannot say any word of miracle again. It also has valuable in healing field. Starting from clearly understood of Qigong, we may easy to understand the valuable for human being and disclose the secret cover.

Holo-Cosmic Qigong was created at the end of Ching dynasty (year 1901) by Master Xiao Chang-ming (called "Holo-Cosmic qi master" 1895-1943 A.D., Xiao was the surname), so far 100 years has passed, followers from generation to generation were found everywhere in the world. This method was easy to learn and use, curing people of their illnesses and removing their sufferings, to reduce pressure and keep fit. One can dispel illnesses and prolong life, and also it can be mastered by oneself and enhances the wisdom and accomplishments of mind and body.

\section{The Valuable of Qigong for Human Being}

General practice of Qigong has three systems:

\section{Physical Exercise}

Connecting with breathing air dumps litter out and let all the origins moving smooth as blood circulation without blocking so that there will be less disease.

\section{Meditation}

Joining with calm down environment, blood circulation will be smooth inside the body. Dumping out all litters and deep rest will make the origins balance transaction, and then the quality of health will increase.

Abraham Shue Yan Poon, Master, Part-time Teacher, The Water Harmony Society. 


\section{Auto-Exercise}

Breaking the exercise power inside and part of that will conjunct with breathing air. It will take strong self-correction of body.

When we use the Holo-Cosmic Qigong to analysis, it means the adjustment and transfer of energy. The exchanging of energy is between the body inside and outside. It will increase the power of body. It is the highest level of Qigong. It is because all materials are made by energy and they can inter-exchange.

The main objection of Holo-Cosmic Qigong is healing the diseases. Individual practice will be at the same time. We use the innate energy (先天之点, quantum energy) to cute the diseases. It will not damage our pure energy inside. Healing and practice will join together. We use 20 characters philosophy, include "loyalty”, "altruism”, “integrity”, “straightforwardness”, “magnanimity”, “uprightness”, “righteousness”, "trustworthiness”, “forbearance”, “impartiality”, “universal brotherhood”, "filial piety”, "benevolence”, “mercifulness”, “comprehension”, “temperance”, “frugality”, “genuineness”, "propriety”, and "harmony” to back up us. We combine with science, medical, and philology as fundamental and use more than 100 years. Innate means the energy that is the beginning of the universal. That is the original energy of all materials. We use this natural energy to put inside to the body of sickness. It will let the body making healing hormone and push the nerves system to send out the repairing plus to our unhealthy area. It is good for healing and better than normal breathing air exercise. On the other hand, it can increase our positive thinking to make health and spirit valuable for all human being.

If you are going to learn Qigong, you must have a good instructor who must know to correct any wrong exercise. It will avoid any wrong direction. The instructor cannot only see the money and take care the rich student. It has some crisis, for example, physical exercise will damage the muscle and the bone. Meditation will make psychical pressure. Auto-exercise will become spirit disease. If you follow the instructions, understand the philology fundamental and modern world-wide Qigong basic ideas, you will not add any confliction and the wrong ways will not happen. You can have more healthy and happiness.

\section{General Terms}

\section{Qigong}

“Qi” means innate qi (点, energy, 先天之墨, quantum energy) and “Holo-Cosmic qi” means all original universal energy. It gives birth to any substance and changes, so it is called innate qi, which is different from specific materiality of acquired qi (後天之氣, air). Harmonizing and combining one's body energy with the innate energy of nature is mastering qigong.

Mastering Qigong is to bring the highest level of traditional ancient Chinese health care into full play, it coincides with the modern naturopathy and prevention medicine, the recent western study of energy medical science coincides with the Chinese theory of health preservation. Holo-Cosmic Qigong stresses on relaxation, not on meditation and personal ability, it is emphasized by natural breathing. Its procedures are union of mind and body, union of heaven and human being, and union of virtues between heaven and human being.

\section{Medical Qigong}

The major advantage of Holo-Cosmic Qigong is healing. Innate qi is applied and qi is used and never exhausted. It is simple, effective, and efficient, there are no restrictions of time and place, and there are no taboos. Innate qi enters the body and becomes the necessary substances to produce mutual influences to help 
growth, get rid of dirt, internal and external illnesses are cleared up, and ill gas is entirely dispelled. We raise hands to get sweet dew, dead wood can be alive again with the return of spring, and the fast effects are sometimes amazing. These are exemplified by the relief of pain and lowering of blood pressure. Medical workers are easily trained and there is no need to spend long hours to be able to deliver the external qi to cure people of their ailments, which can provide large-scale medical service. This combines with scientific development to benefit the world. This simple healing treatment is becoming the new development way of contemporary Medical Qigong.

\section{Heal the Mind and Body}

"Heal the mind first before the body" is the specialty of Holo-Cosmic Qigong. It controls the body and adjusts strength, which paves way for the modern treatment of mind and body. This is the foothold for thoroughly facing life, direction, and human life value. Illnesses only can be eradicated by treating the mind and body together and by those who seek medical treatment can with self-reflection change their thinking and direction of human life. The 20 characters philosophies are the spiritual pills for curing illnesses and the treatment cannot do without the forgoing virtues. With flexible application, the 20 characters will become the wonderful medication to assist people and to save their lives.

\section{Belief}

Confidence and self-confidence are very important, changing confidence is to open the bondage of consciousness, and raising self-confidence is to strengthen the consciousness. Incessant raising of one's thinking power and widening one's scope of knowledge will expand the field of the individual's "qi" and this is the basis for practicing one's skill. With the discovery by medical scientific research, increasing confidence will activate the central nervous system and the brain releases joyful hormones, which strengthens physique. During the treatment process, following the innate conception, the qigong master with sincerity and the 20 characters' integrity will increase the "confidence" of the patient. Both will communicate with "trustworthiness" (belief).

\section{Blood Circulation Flows Freely}

The unrestricted active circulation of qi and blood naturally denotes healthiness. Stretching the limbs, using fixed posture to regulate consciousness in quietude, harmonizing and merging internal and external qi, and arriving at the balancing of Yin and Yang, makes the blood of the whole body flowing without obstruction. The entire energy of innate qi can pass through nervous system and meridians, removing clogged places to improve health. "Pain means obstruction" and "Being unobstructed means being free of pain" are basic law. Pain will be lessened or reduced following the unobstructed flowing of blood and qi.

\section{Group Practicing}

Group practicing can combine the individual fields of qi and becoming one of the members among the great qi field can enhance the efficiency of practicing. It is several times better than practicing by oneself and it is beneficial to one's own and others. Group therapy also brings good results and there is no side effect of ill qi communication or no appearance of other opposite effects.

Curing the sick is only a minor skill. If everyone cultivates this technique with a view to help others to be happy, there will be no selfishness, greed, and absurd demand, which makes the society more harmonious and stable. It is reflected by general human nature and self realization brings objective verification. We put aside 
our disgrace, gain, and loss, we care for nothing, and we become free and unrestricted.

\section{Method of Practice}

Holo-Cosmic Qigong is assisted by moving exercise (colored ball of 20 characters). Treatment is essential: practice is the road and the preliminary method is to achieve relaxation and stillness. Good health is derived from strengthening the bodily functions and still practice is to cultivate our disposition. Our body is the pill. The essential lies in treatment to deliver external qi to cure people of their illnesses, which at the same time produces the good results of treatment and mastery. Self-cultivation develops intelligence and ignites potential, including the absorption of universal energy from celestial bodies to strengthen our bodies and moving exercise relaxes our bones and tendons to improve health. These three parts are inter-connected without stages and mastery and learning can be done not in sequence. We use kind-hearted will to enhance the mind and body. The four parts combine together to become the union of universe and mankind. Introversive mastery proactively makes contributions to the society and people. Our own mind and body is refined through practice, and the union of universe and human beings is the expression our good intentions.

\section{Complete Efficacy}

Everyone has a complete field of qi and there is no special requirement. We emphasize on entirety during practice or treatment. The main points are to raise the quality of body and mind without stressing on particularity of meridians and acupuncture points. The complete exchange of internal and external qi is very great. The application of simple idea regulates the operations of mind and body, and concentration of inner qi naturally promotes the spiritual strength. Therefore, one Qigong method possesses all merits of Qigong, which dispels illnesses, prolongs life, prevents and cures, cultivates the mind, and opens the door to intelligence.

\section{Mind Healing and Healing Illnesses by Sentimental Aspirations}

\section{Illnesses Caused the Seven Emotions}

The key to control mood. Man is depicted to be a sentimental animal by poets or scholars. Among all land species, man indeed possesses dignified and distinctive sentiments. It was said in ancient times that man is different from birds and beasts, because "man has a sense of pity in seeing that a child is about to fall into a well.” The Chinese medical practitioner said that man has seven sentiments: happiness, anger, worries, longing, sorrow, fear, and shock. Man has desires besides being satisfied by basic needs and also has desires for emotional happiness. Therefore, six desires are sorted out: (a) eyes-desire for beauty and strange things; (b) ears-desire for pleasant sounds and commending words; (c) nose-desire for pleasant smells; (d) tongue-desire for delicious food; (e) body—desire for comfort and enjoyment; and (f) intention—immoral music, beautiful girls, fame, wealth, and intimacy etc.

Recently, emotional quotient (EQ) is stressed in the West ${ }^{1}$, which points out that man's emotions must be vented and intensive suppression of emotions is not beneficial to mind and body. Senior executives must have higher EQ. Besides, there are no negative personal sentiments and one should have strong feeling for others to feel their emotional condition. In the face of negative situation or of the upcoming of the negative situation, it is

\footnotetext{
${ }^{1}$ Proposed the first time in 1991 by psychologists Peter Salovey of Yale University and Jack Mayer of the University of New Hampshire and amendment to its meaning was made in 1996, but the new concept of "Emotional Intelligence" was extensively disseminated and discussed in the America and prevalent in this world after Harvard University Professor Daniel Goleman the scientific columnist of "New York Times" wrote the "Emotional Intelligence" in 1996 http://info.psychcn.com/enpsy/200110/294932103.shtml.
} 
necessary to find ways to give advice and to settle in order to avoid the sudden outburst of negative conditions, so that various damages and losses can be inestimable. A desire is not simply a demand for material satisfaction and pleasure. Civilized constructions and civilized creations are the momentum for aspirations. Too much greed will burn like fire and is difficult to be extinguished, finally causing harm to our body. Therefore, since ancient times a virtuous person practicing Qigong or self-constraint on morality calls upon people to curtail their greed to reach the target of health preservation.

If we manage our mood well and put our level of satisfaction at a low level, it is easier to quench our desires when our emotions are satisfied and our having enjoyed the processes. The ancients gave a very good suggestion to set our level of emotional satisfaction at the "doctrine of the mean" or at "not better than the superior, not worse than the inferior". The wonder is to compare yourself with the people under worse conditions, and then you have already been far better. When this crucial emotion is under control, desire will not upraise and there will be a feeling of relaxation for the mind and body. The Qigong and Chinese medical practitioner have similar viewpoints on this aspect.

Emotional power. Chinese medicine and Qigong are established based on the same origin. Body, qi, and mind cannot be separated. According to the Yellow Emperor's Canon of Internal Medicine, the saying “夫形者, 生之舍也, 氣者, 生之充也, 神者, 生之制也, 一失位, 則三者傷矣 !” means that body is the external matter, qi is the energy filling every internal spaces, and mind controls the spiritual feelings of mind and body. The three descriptions have their respective functions. If one of them losses its normal function, our body will be suffered and fallen sick. Emotions are deep in one's heart and they can be felt only by the existence of self-consciousness, so they are frequently ignored by people.

Man's intention and emotion can be classified into two types, namely, consciousness and unconsciousness. Consciousness is part of the inherent nature with the influences of the external factors of education and living environment, it transforms into the moral principles of man. Congenital soul is the primitive state of life, encompassing wisdom, purity, compassion, and humanity. It unconsciously combines with nature. The stimulation of the seven emotions leads to the increase of consciousness power, which further hinders the harmonizing power between the soul and the self, resulting in spiritual turmoil and substantial emotional fluctuations.

Being mentally deranged, both body and mind rapidly deteriorates to cause illness. With harms on mind and body, the influence on mind is relatively slow. If the injury is life-threatening, our feelings will abruptly become extremely tense. Chinese medical practitioners request controllable emotions and harmony in daily life, work, and rest to resist sudden emotional attacks on our mind. The practice of Qigong is to put away consciousness to pacify our mind, alleviating the emotional turmoil. Both have the same functions, though different techniques are applied.

\section{The Congestion of Liver and Qi}

The importance of emotional outlets. According to Chinese medical practitioner, liver is classified as wood in the five elements. "A tree likes to branch off nourishing the stem and leaves, liver is chiefly responsible for the metabolism and detoxification for various bodily organs, so it is similar to a tree”3. Trees

\footnotetext{
${ }^{2}$ Page 36 of “Chinese Qigong Knowledge”edited by Zhong-peng Lin. The first edition was published by Peking Institute of Physical Culture in November 1988, ISBN7-81003-135.

3 The knowledge of five elements and five internal organs, http://hk.knowledge.yahoo.com/question/?qid=7006121400810.
} 
depend on the stems and branches to transport nutrients from the roots to the flowers and leaves at the top. If there are blockages, the flowers and leaves cannot obtain the necessary nutrients, then the trees will wither. Mind and body are under an unified unit. Emotional disharmony impedes the circulation of qi, naturally and directly affecting smooth flow of qi in the internal organs. This leads to the congestion of liver.

According to modern medical analysis, there is a large amount of enzymes in the liver. The liver is the largest detoxifying organ and it stores one third of our body blood. Upon requirement, the liver blood will be immediately delivered to the required organs. Any obstruction sustained to the liver affects the circulation and delivery of blood. The toxic substances in the blood will increase, affecting the supply of blood and oxygen to the brain and causing physiological disorder. The more acute case will cause emotional turmoil.

According to the study of emotions by the Japanese, a happy hormone is secreted by the brain under happy conditions. Chun Shan Mao Xiong wrote the "Revolutions in the Brain"4 which has detailed explanations on his study. According to some foreign detailed study, different emotional expressions produce different hormones. Melancholia causes the secretion of emotional hormone leading to myocardial infarction ${ }^{5}$. If people use different ways to vent their negative emotions, happy hormone will gradually increase. This improves living conditions and changes one's whole life. The harmonization of the mind by Qigong can ease the sluggishness of qi and vent emotions.

Blood circulation being sluggish. Traditional Chinese medicine centers on "blood circulation". To prolong one's life, “Unobstructed blood circulation and being free of diseases” must be maintained. Oxygen is used in metabolism and blood circulation system. Blood is a circulating substance carrying nutrients to cells and organs and carrying away waste substances for excretion from the body. Blood maintains a smooth operation inside the body. If the immune system is strong, the body is strong, too.

Besides genetic factors, most diseases are contracted from external sources because of lower bodily resistance against diseases. Some diseases may turn out to be serious and difficult to heal because of the prolonged unawareness by the patient. If self-healing power is extensively abused, one will fall sick because of cold or infection by germs. From another perspective, it is caused by lack of vital energy and malfunction of immune system. Blood circulation problems undermine the protective mechanism.

Modern medicine interprets that blood contains $90 \%$ of water, thus the fluent movement of water is important. Under the microscope, perhaps we know that the water molecules forming natural snowflakes appear to be of regular hexagonal structures. According to the book Answer to Life-Water Knows" ${ }^{\text {, }}$ by Jiang Ben Sheng, it illustrates that water has spiritual intelligence. Positive emotional expressions, such as kindness cause the water to form hexagonal structures. Reversely, negative emotional expressions can distort water molecular structures to become ugly and irregular. Seventy percent of our body is water. If negative emotions distort water molecules blocking the movements of blood and fluids, it impedes blood circulation and becomes concerns for diseases. Chinese medical practitioners stressed on blood circulation and body relaxation. Mental depression causes other pathological changes. Qigong claims on relaxation to sooth blood and qi circulation.

\footnotetext{
4 "The Great Revolution in the Brain World---brain hormones create different human lives", written by Haruyama Shigeo, translated by Wei Zhu En, published by The Creativity Publisher. In 1987, Doctor Haruyama Shigeo founded the countryside hospitals in Kanagawa county and Yamato city and headed the hospitals. ISBN:9569567112.

5 Reported by Hong Kong “Sing Po”-newspaper on March 6th, 2006.

6 The Japanese Doctor Emoto Masaru, the publisher Ru He, ISBN:9576078318, a series of writings "The Truth of Happiness" and "Water Knows" etc.
} 


\section{Combination of Mind and Body}

Unification of heaven, earth and human. From modern academic research, the mystery of the earth and heaven is unveiled. Though the understanding of the nature by man is still limited, many things in the universe can be observed objectively. Spacecrafts and satellites are built. The earth underneath is always being studied to exploit underground resources. Through science, man knows his littleness but he can stand erect in the world, creating civilization and managing the earth.

Do not look down upon the seven human emotions that can spoil the harmony among people and the balance between heaven and earth. Trees are cut down to satisfy the needs of human civilizations, thus rain forest in Amazon River of South America has been reduced by 20\%, comparing to 40 years ago and 7,700 square miles of forest continue to lose every year. Glaciers melt because the production of carbon dioxide and greenhouse gases by human beings. Global warming can be evidenced by the glaciers in the Andes of Southern Peru and Qori Kalis. Glaciologist Thompson pointed out on February 15, 2007 that according to the present melting speed, it is estimated that this glacier will have completely disappeared by $2012 .^{7}$

Healing both mind and body. The worldly medical trend aims at naturopathy. Many popular treatment methods are adopted besides using natural herbs. Global information is well-developed, the mainstream medicine has been verified, the unwanted information is discarded, and the essence is retained gradually taking up medical skill in every locality. The classification of herbs is gradually complete. The control of slightly toxic varieties is enhanced to protect the rights and interests of the sick.

Different medical healing methods are different in different parts of the world because of differences in civilization. These differences cannot be systemized in a short period of time. On the contrary, Chinese Qigong has the same origin as the Chinese medicine. A complete medical system can be constructed after going through years of experiences, practice, and theories. Therefore, the construction should be expedited to benefit all humans. In addition, Qigong treatment saves a lot of our resources, being beneficial to environmental protection and to the dedication to the health-care of mankind.

Modern medicine has returned to the origin of Chinese Qigong, that is, the "Holistic Medicine”. Many methods are simultaneously adopted to heal the sick. The arrogance of individual medical skill is gradually decreasing. On another respect, the combined healing of mind and body is understood, taking care of the sick of their emotional changes and even of influences by their daily lives. Ancient Chinese medical practitioners brought up the ideas of curing illness spiritually. In early Republic of China, there was also a Qigong master "Xiao Chang-ming”, proposing the curing of illness by philosophic theory. Philosophy was also applied as a form of medication in curing the mind and body. His book Explanation of Spiritual Healing (Five elements correspond to eight trig-rams) argues fire being in charge of ceremony is for qi, burning hotly and brightly. Looking at this present generation, public feeling is not generous, the fate of the generation is weakening, moral is completely ruined, material life is cherished clouding our mind, and people are dominated by modern trends, being soiled by seven emotions and attacked by six sensory pleasures. In addition, the weather changes unexpectedly, so Yin and Yang are in disharmony, and river water is poisonous. Human life is to be pitied, and therefore, the 20 words are created. These 20 words are the righteousness of the universe, making people stick to virtues. Being diligent and vigilant all day, and being the body of righteousness, so that the heart is brightened up. "I started the spiritual therapy to study the phenomena of nature to acquire knowledge, those

\footnotetext{
${ }^{7}$ ETTV Taiwan: http://tw.news.yahoo.com/article/url/d/a/070216/17/amwy.html.
} 
with heart illness are treated with etiquette, those with liver illness are treated with benevolence, those with spleen illness are treated with trustworthiness, those with lung illness are treated with righteousness, and those

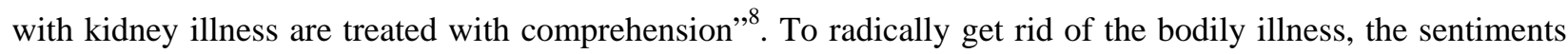
must be tuned up at the same time in order to harmonize the mind and body. Those come to the final conclusion by Master Xiao Chang-ming that "The mind is cured first before the illness is cured". This is the highest radical treatment harmonizing mind and body to lead a healthy, happy, and meaningful life.

\section{Conclusion}

Holo-Cosmic Qigong was breakthrough the traditional qigong because it has been developing the theory of primordial qi since 1901 by Great Master Hsiao Chang-Ming. He also set up to cure illness and then to re-harmonize the mind. The extreme benefit is to healing large mumbers of illness. To obtain the positive energy of Holo-Cosmic qi (primordial qi) from the space to cure illness as well as to heal the mind. The technique is simple. It makes the qigong as the ultimate application of nature medicine, enviro-medicine, energy medicine, prevention medicine and the poinner of positive psychological medicine. It accomplishes the unity of the validity and the practical usefulness of medicine, science and philosophy. It illustentes the traditional theory of qigong and the modern theory of contemporary medical qigong or holistic medinice. Holo-Cosmic Qigong has the big step forward of contemporary Medical Qigong. It combine healing and self-improvement. Holo-Cosmic Qigong will serve people for better health as great benefit.

\section{References}

Dictionary of Common Qigong Glossary. (n.d.). Shanghai Scientific \& Technical Publishers.

POON, A. (n.d.). Peaceful Song Within The History · The Legend of Grrat Master Hsiao Chang-Ming.

Tak Chong King. (n.d.). Tainan.

The rutuge of Tien Tak St Cow for 46 Years. (n.d.). Heven's Magnanimity and Holy Teaching Religious.

\footnotetext{
${ }^{8}$ The article was issued in 1929, other writings also addressed many new viewpoints of healing illness. Later on, left behind was the manuscript “Simple Explanation on Spiritual Healing”. Qigong practitioner Gui-wen Bao one of his followers was, in the eighties, famous all over the national capital.
} 